\title{
Causal relationships or casual associations? Assessing the nature and character of mental illness/disorder and crime
}

\section{Dr Ian Cummins}

Salford University

\section{Introduction}

The link between mental illness, violence and other offending remains an area of controversy. The debate can become polarised around two extremes: that no such link exists or the mentally ill as a group are violent. This chapter will place these debates within the context of the development of two interrelated policies - the expansion of the use of imprisonment and deinstitutionalisation. One of the most startling features of social policy development over the past thirty years is the expansion of the use of imprisonment. In the 1970s, criminologists were seriously considering how the prison as an institution was on the verge of disappearing and pondering how it would be replaced as the central penal mechanism in liberal democracies. The overlap between mental health and the criminal justice system is a well-established one. The CJS has become a default provider of mental health care in many instances. The chapter will conclude with a brief discussion of Penrose's hypothesis which identified a hydraulic relationship between the use of imprisonment and the use of institutionalised forms of care for mental illness.

Mental health issues in the Criminal Justice System

There is a tendency to view the CJS and mental health systems as distinct entities that occasionally overlap - for example in forensic mental health provision. This is misleading. The boundaries between the two are much more porous than is generally acknowledged (Seddon, 2007). It is a combination of factors that leads to some individuals in the CJS being recognised as having a mental health problem. It is important to acknowledge here that the overwhelming majority of professionals working the CJS do not have formal mental health qualifications. 
Mental health problems can be masked by drug and alcohol misuse. These combined with the nature of the environment in police custody suites, the Courts and prisons mean that offenders with mental health problems may not have their needs identified or addressed adequately. Foucault (2012) emphasised that the prison as an institution has always been used to accommodate a variety of individuals labelled as deviant by the wider society.

There is a danger of presentism in all areas of social policy. This is particularly the case in the fields of mental health and its intersection with the CJS. In 1780, John Howard carried out his famous inspection of the state of the prisons in England. As well as describing the appalling physical conditions that led to disease and hunger, the corruption amongst warders, Howard noted that the prisons were housing more, what he termed “idiots and lunatics". In addition, Howard indicated that the increases in the number of what we might now term "mentally disordered offenders" meant that the prison regime was unable to meet their needs. This had a detrimental effect on the prison regime for all those in prisons. Similar observations have been at regular intervals since. However, the recent expansion in the use of the imprisonment has occurred during the period when the impact of deinstitutionalisation has been most cleanly felt. The combination has exacerbated these problems. The CJS has become something of a default provider of mental health care. This is the case across all the stages of the CJS. The result is that more CJS professionals are being asked to take on roles or tasks that involve responding to individuals experiencing mental distress.

\section{The problem of definition}

One of the most fundamental issues that debates in this field raise is - what is the definition of the term mentally disordered offender? At its narrowest, the term might only be used for those convicted of offences and sentenced under the provisions of the Mental Health Act (1983). This is a very small group and it is also does not cover those who people with mental health problems who are in contact with the police or in police contact. At its broadest, it could include anyone in contact with the CJS who has mental health problems. This is a very wide definition and includes groups with varying needs. It will thus include acutely unwell individuals who might be admitted to a mental health unit but also those who 
would be treated as an outpatient. This definition acknowledges the porous nature of the boundaries between the CJS and mental health systems. The use of the term "offender" is more problematic. For example, if someone is detained under section 136 MHA by a police officer, they have not committed any offence but they have been drawn into the CJS by virtue of their contact with the police. The limited research that explores the experiences of people detained under section 136 indicates that they see it as a punitive rather than therapeutic intervention. Law and policy allows that the mental health of an individual can and should be a consideration in decisions at every stage of the CJS. This is the case from potential contact with a police officer on the street, through custody, charging and sentencing. The police, Courts and prisons can be viewed as a series of filters(Cummins, 2016).

\section{Policing and mental illness}

The role of the police in responding to people who are experiencing some form of mental health crisis has come under increasing scrutiny. There are concerns from the police that they are being increasingly called upon because of the gaps in community mental health services.The Police have considerable discretion in terms of their response but have always had a role in responding to those experiencing mental distress. The general police role of maintaining public order will inevitably include what we might term welfare work - looking for missing people for example. The police role is thus a combination of preventing crime, detecting and apprehending those who have committed offences and a more general one (Bitner 1967). This has always been the case since the establishment of the modern police force. However, it is clear that the pressures have increased since the development of deinstitutionalisation and the policies of austerity adopted since 2010 (Cummins, 2013). Lord Adebowale (2013) described mental health as "core business" for the police. His study confirmed earlier work by the Sainsbury Centre (2008) which had concluded that between $15-20 \%$ of police work relates to mental health issues. A very significant proportion of this work involves dealing with cases where people with mental health problems are victims of crime. To this must be added, cases where people with mental health problems have committed crimes, mental health emergencies and section 136 MHA, supporting community mental health services and ensuring that people in custody are safe. 


\section{Mental disorder and offending}

The above forms the policy context which create the environment, in which, mental health and CJS professionals work. As outlined above, there is considerable overlap between the two groups, who are often responding to very similar situations. Cummins (2013) outlined that the thrust of policy has been to divert individuals with mental health problems from the CJS at the earliest opportunities. The current difficulties in both prisons and mental health services illustrate that diversion, if it is achievable, requires robust and well funded community mental services.

The problem of defining the term " mentally ordered offender" contains within it two difficulties -what do we mean by mental disorder and who is considered an offender. Both terms cover huge ranges of behaviour. Both fields a number of ethical and philosophical issues. Eastman and Starling (2006) note a purely biomedical model of illness cannot transferred easily to mental health. We see mental illness, if we accept the term at all in the impact it has on an individual's behaviour, thoughts and language. The reason why we think people are ill is because they are "behaving oddly". It is a very powerful cultural trope that sees mental illness, particularly, the most serious forms, as changing the character or personality of an individual. This is reinforced in cultural representations of mental illness (Cross, 2010). The existence and impact of mental illness has huge implications in the CJS field. In particular, it forces us to consider the key questions of autonomy and responsibility are being considered. Psychiatric diagnosis has a role to play in the CJS. This means that the Courts can be the site of debates about diagnosis and the impact on responsibility. Legal and policy changes have an impact on the way that these debates are constructed. The reform of the Mental Health Act (2007) has seen the creation of the term "dangerous and severe personality disorder". This term is, in effect, a legal categorization cloaked in terms of psychiatric discourse.

One of the core notions of the Anglo-American legal tradition, is individual autonomy. Individuals are free to act or are autonomous. The individual is not coerced into committing an offence. An individual must have been in a position, in 
which, they could make a choice. This model has important implications for the legal treatment of offenders, who are mentally disordered. Nagel (1970) suggests that behaviour is intentional if the individual acts on a belief or desire. These must be independent and pass what he terms "critical scrutiny". An individual who is forced or coerced to take part in a criminal enterprise could argue that they were not responsible. The final leg of Nagel's schema is that the beliefs and desires that are the spring for action will pass critical scrutiny. Lipkin (1990) uses the example of John Hinckley. Hinckley's shooting of President Reagan was the result of a delusional belief system, in which, not only did the President approved of his actions but also they would lead to Jodie Foster of becoming his lover. Both ideas are so bizarre that they could not pass any critical scrutiny. Therefore, Hinckley's mental illness and the delusional beliefs he held were the cause of his attempt to assassinate the President of the United States. He should be viewed in a different fashion to someone who commits a murder in the course of a robbery. This is clearly a rare and highly unusual example. However, it demonstrates the fundamental principles that need to be consideration.

Punishment is based on the notion that the offender took a conscious, rational decision to ignore or break the law. They were not coerced. Thus an offender can only be punished if they deserve it because they have committed the offence and there is a positive outcome for society. This is usually justified by reducing offending by both that individual and the wider deterrent effect. Offenders are viewed as moral agents, who have chosen a particular course of action. Becker's (1968) influential Rational Choice Theory of offending is the clearest exposition of this approach. It argues that offenders essentially carry out a form of cost benefit analysis before deciding to commit an offence. In this analysis, they consider the chances that they will be caught, the possible punishment and the rewards of the crime.

Mental disorder has impacts on thinking and how we view the world. In the legal sphere may prevent the formation of mens rea. A fundamental question is the extent, if any that mental disorder can be said to lead to an offence. A legal defence of insanity is based on the idea that mental disorders affect reasoning and decision making ( Morse, 2003) There is a further complication here in that the 
links between mental illness and offending are not as straightforward as this line of argument suggests. The Hinckley case is very unusual. It was possible for the defence to demonstrate a clear links between the delusion ideas and the shooting of Ronald Reagan. The majority of cases are not like this. However, leaving aside the issue of substance misuse and addiction, it is largely agreed that individuals are not responsible for the symptoms of mental illness and that such symptoms can affect the individual's ability to act as a moral agent.

Eastman and Starling (2006) strongly argue that mental illness is an issue for the CJS because of its affects on individual autonomy. It is a matter of degree that is altered by not only the nature and severity of the mental disorder but other factors such as the efficacy of a particular course of treatment. It is important to note that mental disorder cannot be used to explain all offending. It can only be used to excuse or be part of mitigation for those offences where the disorder affected the reasoning that led to the commission of that crime. There is an inherent danger that the portrayal of the effects of mental disorder is to turn those experiencing mental distress into machines. As well as being philosophically problematic Morse (2003) suggests that such accounts are inaccurate. He argues that a hallucinating person retains the ability to act intentionally, to act for reasons. John Hinckley both had clear reasons for acting in the way they did. The issue for the Criminal Justice system is to what extent the delusional basis of those reasons should be seen as a mitigating factor.

The issues of autonomy, responsibility and the extent to which mental illness should be seen as a mitigating factor are played out in the Courts. The case can become not about whether an individual carried out an act. The questions under consideration are more concerned with the existence and any potential impact of mental illness on the defendant. The trial of Peter Sutcliffe the so-called Yorkshire Ripper is a high profile example of this. He entered a plea of guilty to manslaughter on the grounds of diminished responsibility. This was initially accepted but then rejected by the Crown. The trial then, in essence, became a debate about whether Sutcliffe was "mad". It involved psychiatrists for both the defence and the prosecution arguing their positions. It was for the jury not, the mental health professionals to settle ultimately the question. Sutcliffe was found guilty and 
sentenced to life for the brutal murders of thirteen women and seven further cases of attempted murder (Bilton, 2003). Sutcliffe was transferred to forensic mental health services in 1984. He spent thirty-two years there before being transferred back to a maximum security prison in 2016.

\section{Imprisonment}

One of the most significant features of social and public policy in the UK in the past thirty-five years has been the consistent rise in the number of people in prison. The UK has been not alone in developing what has come to be termed a penal state (Cummins, 2016). There are four nations of the UK, with differing legal and sentencing systems. The focus here will be on England and Wales. The USA has seen the greatest increase in the use of imprisonment. There are over 10.2 million people in prison. 2.4 million of those are in prison in the USA. Three countries, the USA, Russia (0.68 million) and China (1.64 million), hold roughly a quarter of the world's prisoners (Walmsley, 2013). Walmsley (2013) concludes that prison populations have continued to grow across the five continents since the turn of the century. The standard comparative measure for imprisonment is the rate per 100, 000 of the population. Since 1999, the overall world prison population rate has increased from 136 per 100, 000 to 144 per 100, 000. The USA remains at the top of this incarceration league with a rate of 716 per 100,000 .

The USA should be viewed as both an outlier in terms of penal policy but also, I would argue a warning of the damage that mass incarceration can do to individuals, communities and the wider social fabric. In his analysis of the development of mass incarceration, Simon (2014) highlights three key drivers. A fear of crime and the political fallout from being seen as weak on the issues leads to a ratcheting up in sentencing. Custodial sentences replace community penalties or supervision. Custodial sentences become longer - driven by a the perceived need to be tough on crime. In the USA, this was driven by the war on drugs. Finally, mandatory and or indeterminate sentences are introduced (Simon, 2007). These factors combine to produce a perfect storm. All these factors are present to a greater or less degree in the British context. Progressive parties have been unable or unwilling to shift the terms of the debate for fear of being seen as soft on crime. The impact of imprisonment is not limited to individuals who are sentenced by the Courts. In the USA, these impacts have to be viewed through the prism of race. 
There is a significant body of research that demonstrates the wider damage that has been done to the African- American community ( Drucker, 2011). Many US states prevent ex prisoners from voting, accessing social housing or completing educational programmes. This serves to create a new "caste" of disenfranchised and marginalised young black men Alexander (2012).

England and Wales is the jurisdiction in Europe that has seen the most dramatic rise in the use of imprisonment. This increase and its impact have not been, until relatively recently, the centre of any concentrated political debate. Recent statements by both the Prisons minister, Rory Stewart and the Justice Secretary, David Gauke have indicated a shift in approach. They have highlighted the need for a more constructive prison regime, questioned the effectiveness of short sentences and recognised that the impact of drug and substance misuse on prison regimes. These statements have to be viewed in the context of the development of a prison regime that has seen the number of prisoners rise, whilst there have been significant cuts in the number of prison officers. There were 64,000 people in prison in 2000, this rose by a third to over 86,000 in 2012. On average it costs around $£ 38,000$ per year to imprison someone and one has to ask whether these huge sums of money represent the best use of public funds. Recidivism rates are poor with $73 \%$ of those aged under 18 years sentenced to custody reoffending within 6 months of release.

In addition, serious questions are now being asked about how safe prisons actually are, with 88 suicides in prisons in England and Wales in 2015. Put this bleak figure alongside reports of violence towards staff, bullying and lack of constructive activities and the result is a toxic mix (ref for HMIP report).

\section{Mental health care in the prison setting}

One of the key contemporary policy concerns is that the CJS is being increasingly asked to provide mental health care. The Trencin statement (WHO, 2008) commits governments to provide the same level of health care to prisoners as the general population. It states that:

Prisoners shall have access to the health services available in the country without discrimination on the grounds of their legal situation. 
This is an important moral and ethical statement. It is an aim that many governments have failed consistently to achieve. The expansion in the use of imprisonment and the overcrowding that often accompanies it makes it difficult to provide appropriate ongoing care. Those sentenced to imprisonment do not represent a cross-section of the population. They come from overwhelming poor, marginalised and urban communities. Marmot (2010) has demonstrated the impact of social inequalities on health - both physical and mental. There is a clear gradient in health. Karban (2016) has highlighted the need for a health inequalities approach to tackle the most deeply engrained mental health issues. These problems have been exacerbated by the impact of austerity (Cummins, 2018). Cuts public services inevitability have the greatest impact on those most in need of services. There is a pincer effect here - demand for services increases at the time that the services are under greatest pressure. The health care needs of prisoners are much higher than those of the general population. These reflect the socio-economic background of the prison population but also the impact of other factors such as alcohol and drug abuse.

There are additional problems providing mental health services within a prison environment or across the CJS. The starting point is a statement of the obvious fact that a police or prison cell is not and can never realistically hope to provide a therapeutic environment. In addition, security and other organisational needs will mean that prisoners might be moved at short notice and so on making it difficult to provide consistent care. Prisons can be brutalising environment so may create or exacerbate mental health problems. The impact of mass incarceration was demonstrated in the case of Brown v. Plata in the USA, (Simon,2014). Prisoners sued the state of California - and won - on the basis that the state had failed to provide adequate health care. This included mental health care. The case went to the Supreme Court which found 5-4 in the favour of the prisoners. In writing the majority decision, Justice Kennedy emphasised that prisoners retained the essence of human dignity. Any prison regime that provided such inadequate care violated this fundamental concept.

One of the major concerns of academics, policy makers and campaigners who seek to reduce the numbers in prison, is that many prisoners experience mental 
illness. In addition, there are concerns that this group of prisoners do not receive appropriate care and treatment. Singleton et al (1998) is now twenty years old but remains the benchmark study in the UK of the mental health needs of prisoners. Fazel et al (2012) carried out a meta analysis of studies of prisoners mental health. Prisoners experience higher rates of mental illnessSurveys estimate that one in seven prisoners are diagnosed with depression or psychosis. These figures appear to have remained unchanged for over a decade Research has also consistently demonstrated high rates of comorbidity between mental illness and substance misuse. This combination has profound health and social implications. Treatments are not as effective and reoffending rates are higher.

Rates of psychiatric disorders and drug dependence are much higher amongst female prisoners. The poor mental and physical health of women in prisons (and the need for alternatives to imprisonment) was outlined in the Corston Inquiry (Corston, 2007)

Fazel et al (2012) study indicates that prisoners are a particularly at risk group for suicide and self-harm. In male prisoners the rates are 3-6 times higher and for female prisoners the rate is 6 times higher than the wider community. It should be noted that the risk factors for self-harm and suicide such as drug and substance misuse problems, experience of abuse and/or sexual violence are all higher amongst men and women in prison. There are differential patterns identified here, including lower rates of suicide and self-harm experienced by black, Asian and mixed race prisoners.

Fazel et al (2012) also examine is violence and victimisation. People with mental health problems are more likely than other groups in the general population to be subject to violence. Violence is almost taken as a given of daily prison life but there is little research that examines its prevalence. Studies indicate that physical assault is 13-27 times more common in prison than in the community. The prison culture makes it difficult to carry out work in this area as assaults are likely to be under-reported, mostly because of the possible consequences of being seen as an informer. Fazel et al (2012) concluded that both male and female prisoners experiencing mental health problems were more vulnerable to sexual violence and physical assault. 
This detailed piece of work demonstrates that the rates of mental disorder are higher amongst prisoners than the wider community. This is particularly the case for serious mental disorders such as psychosis and depression. In addition, about $20 \%$ of prisoners have a substance misuse problem.Features of the prison environment (higher levels of violence, bullying and intimidation alongside the availability of new psychoactive substances such as spice) increase the risks to mental health.

Fazel et al (2012) argue that there is a need for a robust and systematic assessment of prisoners for mental health problems, alongside acute detox services on arrival at all prisons. Alongside these, the need for the provision of trauma-focused and gender specific interventions within the prison setting and the development of suicide prevention strategies including monitoring and assessment of prisons and staff training. These recommendations are calling for the current best practice in community mental health to be applied to the prison setting.

\section{Conclusion}

The prison and the asylum are two of the key institutions of modern welfare states (Foucault, 2003 and 2012). They can regarded as separate and distinct regimes - one punitive the other therapeutic. This is a very limited analysis that does not take account of the symbolic and functional roles that they both had in the management of social deviance. There is an argument that the failure of community care has seen the distinctions between them become even more blurred and confusing. As we have seen above, the debates about the nature of mental illness and its potential links with offending behaviour continued to be played out in Courts and other settings. This not to suggest that people with mental health problems are more likely than others to commit crime. It is rather an acknowledgement that in some, if not, the majority of cases, it can be difficult if not impossible to establish conclusive casual links between specific symptoms of mental illness and the commission of offences. Even where this is the case, it is still possible to argue that the offender shoudl be punished. 
Penrose (1939 and 1943) put forward the intriguing hypothesis that there is a fluid relationship between the use of psychiatric inpatient beds and the use of custodial sentences. The 1939 paper was based on the analysis of statistics from European countries and argues that there was an inverse relationship between the provision of mental hospitals and the rate of serious crime in the countries studied - as one increases, the other decreases. The 1943 paper was a study of the rates of hospital admission in different states in the USA and the numbers in state prisons. Later in his work, he argued that a measurable index of the state of development of a country could be obtained by dividing the total number of people in mental hospitals and similar institutions by the number of people in prison. The policies of deinstitutionalisation and the development of the penal state appear to support the main thrust of Penrose's argument. He suggested that society responds to deviance in one of two ways, either by medicalising it of punishing it.

Penrose's hypothesis could be criticised for equating mental illness with criminality. I would suggest that this his not his intention. He was rather arguing that we should not criminalise the mentally ill. He supported more therapeutic interventions and approaches. The development of community based mental health services is based on both moral and clinical arguments. Its main proponents, for example, Basaglia in Italy saw the institutionalised treatment of the mentally ill, as a political issue, one of human rights (Foot, 2015, Cummins, 2016). Community based services, it was argued, would be by definition more humane.Those who argued for community based mental health services did not envisage that asylums would be replaced by police and prison cells. Deinstitutionalisation, a progressive policy aimed at reducing the civic and social isolation of the mentally ill, has not achieve its aims. Wolff (2005) and Moon (2000) argue that asylums have been replaced by a fragmented and dislocated world of bedsits, housing projects, day centres or increasingly, prisons and the criminal justice system. This shift has been termed 'transinstitutionalisation'.

The policy of deinstitutionalisation is followed across the world. At the same time, there has been a clear shift towards a more punitive prison policy. As Wacquant (2009) argues, throughout the industrialised world there has been a large prison 
building programme and investment in the criminal justice system. Gunn (2000) and Kelly (2007) found that the reduction in the number of psychiatric beds in the UK occurred at the same time as the rise in the prison population, as Penrose predicted. The clash of the two policies outlined above - deinstitutionalisation and mass incarceration seems to provide evidence to support Penrose's original hypothesis. Large and Nielessen (2009) undertook a review of Penrose's original hypothesis using data from 158 countries. They suggest one of the main features of Penrose's argument is that there is a unchanging proportion of any population that will need, or be deemed to need, some form of institutional control. They concluded that though there was a positive correlation between prison and psychiatric populations in low and middle income countries, there was no such relationship in high income countries

Penrose's hypothesis can be seen as as a statistical argument. The examination of the relationship between two major institutions- prison custody and psychiatric care. There are a number of problems that arise here. Such an approach equates crime and mental illness. In addition, it fails to explore the reasons behind the changes in patterns of use of the two institutions. The increase in the use of prison continues despite the general reduction in the crime rate (Garland, 2001). Therefore, it is part of a wider change in society and government attitudes rather than simply a response to crime. The changes in the use of institutional psychiatric care are the result of a combination of social attitudes, improved medical and treatment approaches, recognition of the cost of in-patient treatment and recognition that citizens should not lose their civic and human rights because of mental ill-health.

As outlined above, there is a danger that "mad" or "bad" limits our understanding of the causality of offending whilst at the same stigmatising mental illness. There is a further danger that it will fail to recognise that the term "mentally disordered offender" or any variation thereof will include a wide range of individual experiences. If it is only used in circumstances where the defence make clear links between symptoms of mental illness and offending then it will be used increasingly rarely. There is a further danger that the conclusion of the "mad" / "bad debate is that we see the options as either treatment or punishment. This 
would constitute a clear breach of the Trencin statement. We need to reaffirm that the CJS should be based on the fundamental principle of a recognition of the dignity of all involved. 


\section{References}

Alexander, M. (2012). The new Jim Crow: Mass incarceration in the age of colorblindness. The New Press.

Becker, G. (1968). "Crime and punishment: an economic approach". Journal of Political Economy. 76 (2): 169-217

Bilton, M. (2003). Wicked beyond belief: The hunt for the Yorkshire Ripper. London: HarperCollins.

Bittner, E. (1967). The police on skid-row: A study of peace keeping. American sociological review, 699-715.

Corston, J (Chair) (2007) A report by Baroness Jean Corston of a review of women with particular vulnerabilities in the Criminal Justice System www.justice,gov.uk Cross, S. (2010). Mediating madness: Mental distress and cultural representation. Springer.

Cummins, I. (2013). Policing and Mental Illness in the era of deinstutionalisation and mass incarceration: A UK Perspective. International Journal of Criminology and Sociological Theory, 6(4), 92-104.

Cummins, I. (2016). Mental Health and the Criminal Justice System: A social work perspective. Critical Publishing.

Cummins, I. (2016). Putting diagnosis into brackets: Franco Basaglia, radical psychiatry, and contemporary mental health services. Illness, Crisis \& Loss, 1054137316659206.

Cummins, I. (2018). The impact of austerity on mental health service provision: a UK perspective. International journal of environmental research and public health, 15(6), 1145.

Drucker, E. (2011). A plague of prisons. The Epidemiology of Mass Incarceration in.

Eastman, N., \& Starling, B. (2006). Mental disorder ethics: theory and empirical investigation. Journal of medical ethics, 32(2), 94-99.

Fazel, S., \& Seewald, K. (2012). Severe mental illness in 33588 prisoners worldwide: systematic review and meta-regression analysis. The British Journal of Psychiatry, 200(5), 364-373.

Foot, J. (2015). The man who closed the asylums: Franco Basaglia and the revolution in mental health care. Verso Books.

Foucault, M. (2003). Madness and civilization. Routledge. 
Foucault, M. (2012). Discipline and punish: The birth of the prison. Vintage.

Garland, D. (2001). The culture of control Oxford University Press.

Gunn, J. (2000). Future directions for treatment in forensic psychiatry. The British Journal of Psychiatry, 176(4), 332-338.

Karban, K. (2016). Developing a health inequalities approach for mental health social work. British Journal of Social Work, 47(3), 885-992.

Kelly, B. D. (2007). Penrose's Law in Ireland: an ecological analysis of psychiatric inpatients and prisoners. Irish Medical Journal, 100(2), 373-374.

Large, M. M., \& Nielssen, O. (2009). The Penrose hypothesis in 2004: Patient and prisoner numbers are positively correlated in low-and-middle income countries but are unrelated in high-income countries. Psychology and Psychotherapy: Theory, Research and Practice, 82(1), 113-119.

Lord Victor Adebowale. Independent Commission on Mental Health and Policing. House of Lords, 2013.

Marmot, M., Allen, J., Goldblatt, P., Boyce, T., McNeish, D., \& Grady, M. (2010). Fair society, healthy lives. The Marmot Review, 14.

Moon, G. (2000). Risk and protection: the discourse of confinement in contemporary mental health policy. Health \& place, 6(3), 239-250.

Morse, S. J. (2003). Diminished rationality, diminished responsibility. Ohio St. J. Crim. L., 1, 289.

Nagel, T (1970). The possibility of altruism. Oxford University Press

Sainsbury Centre for Mental Health (2008) Briefing Paper 39 Mental Health Care and the Criminal Justice System

Penrose, L. S. (1939). Mental disease and crime: outline of a comparative study of European statistics. British Journal of Medical Psychology, 18(1), 1-15.

Penrose, L. S. (1943). A note on the statistical relationship between mental deficiency and crime in the United States. American Journal of Mental Deficiency, 47, 462.

Seddon, T. (2007). Punishment and madness: Governing prisoners with mental health problems. Routledge-Cavendish.

Simon, J. (2007). Governing through crime: How the war on crime transformed American democracy and created a culture of fear. Oxford University Press.

Simon, J. (2014). Mass incarceration on trial A Remarkable Court Decision and the Future of Prisons in America New Press 
Singleton N, Melzer H, Gatward R, Coid J, Deasey D. (1998) Survey of Psychiatric Morbidity Among Prisoners in England and Wales. Office for National Statistics, Wacquant, L. (2009). Punishing the poor: The neoliberal government of social insecurity. Duke University Press.

Walmsley, R. (2013) World prison population listed . London: International Centre for Prison Studies,

W. H. O. (2008). Trencin statement on prisons and mental health. Copenhagen: WHO Europe.

Wolff, N. (2005). Community reintegration of prisoners with mental illness: a social investment perspective. International journal of law and psychiatry, 28(1), 4358. 